\title{
MEASUREMENT AND EVALUATION OF SELECTED 14-MEV NEUTRON CROSS SECTIONS FOR FUSION
}

J. W. MEADOWS, D. L. SMITH AND S. A. COX Argonne National Laboratory, Argonne, Illinois, U.S.A.

Abstract Experimental neutron-activation cross-section data in the vicinity of $14 \mathrm{MeV}$ are evaluated for several reactions of fusion-related interest using a least-squares method. New experimental measurements are performed at $14.7 \mathrm{MeV}$ for all of these considered reactions and for some commonly-used standard reactions as well. Comparison is made between measured and

$\because \quad$ evaluated results.

\section{INTRODUCTION}

It is generally assumed that the first generation of fusion-energy reactors will be based upon the $\mathrm{H}-3(\mathrm{~d}, \mathrm{n}) \mathrm{He}-4$ reaction. Thus, knowledge of a variety of reaction cross sections for neutrons at the source energy around $14 \mathrm{MeV}$ is very important (e.g., Refs. 1 and 2). A large body of neutron-cross-section data at this energy has already been accumulated owing to the widespread availability of 14$\mathrm{MeV}$ neutron generators (e.g., Refs. 3 and 4). However, knowledge of the pertinent cross sections is of ten confounded by the existence of large discrepancies between the various reported results. The problem, then, is how to best deal with this dilemma. It is our belief that a reasonable approach is to: i) compile all the reported data, 1i) adjust these data for revisions in nuclear standards and constants, where possible, 111) evaluate the adjusted results using modern and relatively-consistent procedures, and iv) test the evaluated results with some careful new measurements. Completion of this program in a comprehensive manner represents a formidable task, but one which appears to be feasible provided that several laboratories equipped for this purpose address the 1ssue and coordinate their efforts. Our laboratory has undertaken a modest program along this line, and the present paper reports on some of our work to date. We have performed measurements for the twenty reactions listed in Fig. 1. We have also compiled data and evaluated sixteen of these, but have relied on recent high-quality evaluation results from the literature for the other four, as discussed below. A detailed report of our evaluation work appears in Ref. 5 so the present discussion is brief. The present experimental values are preliminary ones. Final values will be published upon completion of this phase of our investigation. 


\section{DISCLAIMER}

This report was prepared as an account of work sponsored by an agency of the United States Government. Neither the United States Government nor any agency thereof, nor any of their employees, makes any warranty, express or implied, or assumes any legal liability or responsibility for the accuracy, completeness, or usefulness of any information, apparatus, product, or process disclosed, or represents that its use would not infringe privately owned rights. Reference herein to any specific commercial product, process, or service by trade name, trademark, manufacturer, or otherwise does not necessarily constitute or imply its endorsement, recommendation, or favoring by the United States Government or any agency thereof. The views and opinions of authors expressed herein do not necessarily state or reflect those of the United States Government or any agency thereof. 


\section{J.W. MEADOWS, D.L. SMITH AND S.A. COX}

\section{EVALUATIONS}

Our evaluation procedure, as described in Ref. 5, follows closely the approach indicated above. The comptled data were adjusted for nuclear-constant revisions (e.g., Ref. 6), and our choices of standard values were based upon state-of-the-art evaluation efforts which preceded our work $(7,8$ and 9$)$. We were satisfied with existing evaluations for four of the reactions in Fig. 1 and did not repeat them ( 8 and 9). A least-squares method was used to account for varying uncertalnties and for correlations between the standards and nuclear constants. However, we have not attempted to evaluate all reactions simultaneously (e.g., as done in Ref. 8). Simultaneous evaluation appears to us to be a rather impractical approach except for a few standards. Our evaluation procedure, as well as those of Refs. 7 and 8 , lead to unceriainty predictions for the evaluations, as given in Fig. 1. For comparison, we have also shown the results of unweighted averaging of our selected, adjusted evaluation data base.

\section{MEASUREMENTS}

The cross-section measurements were performed at Argonne National Laboratory using a Texas Nuclear Generator Model No. 9400 operating at $150 \pm 10 \mathrm{kV}$. Titanium-tritide targets were employed. It was determined that the average neutron energy was $14.74 \pm 0.02$ $\mathrm{MeV}$ and the resolution was $0.324 \mathrm{MeV}$ (FWHM). A low-mass fission chamber containing depleted uranium (U-238) was used as a neutronfluence monitor. All the indicated activities were measured by gamma-ray counting with a germanium detector. The experimental procedures used are described in more detafl in Refs. 10 and 11 . The errors in the measured cros $s-s e c t i o n$ ratios appear to be in the range 2 to 5\%. The uncertainty in the ENDF/B-V U-238 neutronfission cross-section standard is taken to be $4.8 \%$ (7), so the total exror in the measured cross sections is in the range 5.2 to $7 \%$. The preliminary experimental results are plotted in Fig. 1 .

\section{DISCUSSION}

Referring to Fig. 1, we first note that the unweighted-average values are generally in reasonable agreement with the more-rigorouslyevaluated results, considering the combined errors. Thus, once the selection of the data base has been made and adjustments applied, the results of the evaluation seem not to be excessively dependent upon the particular algorithm used in the evaluation. It would appear, then, that the most crucial part of an evaluation procedure centers upon the selection or rejection of the available experimental data, and the adjustments made to the reported values. The 


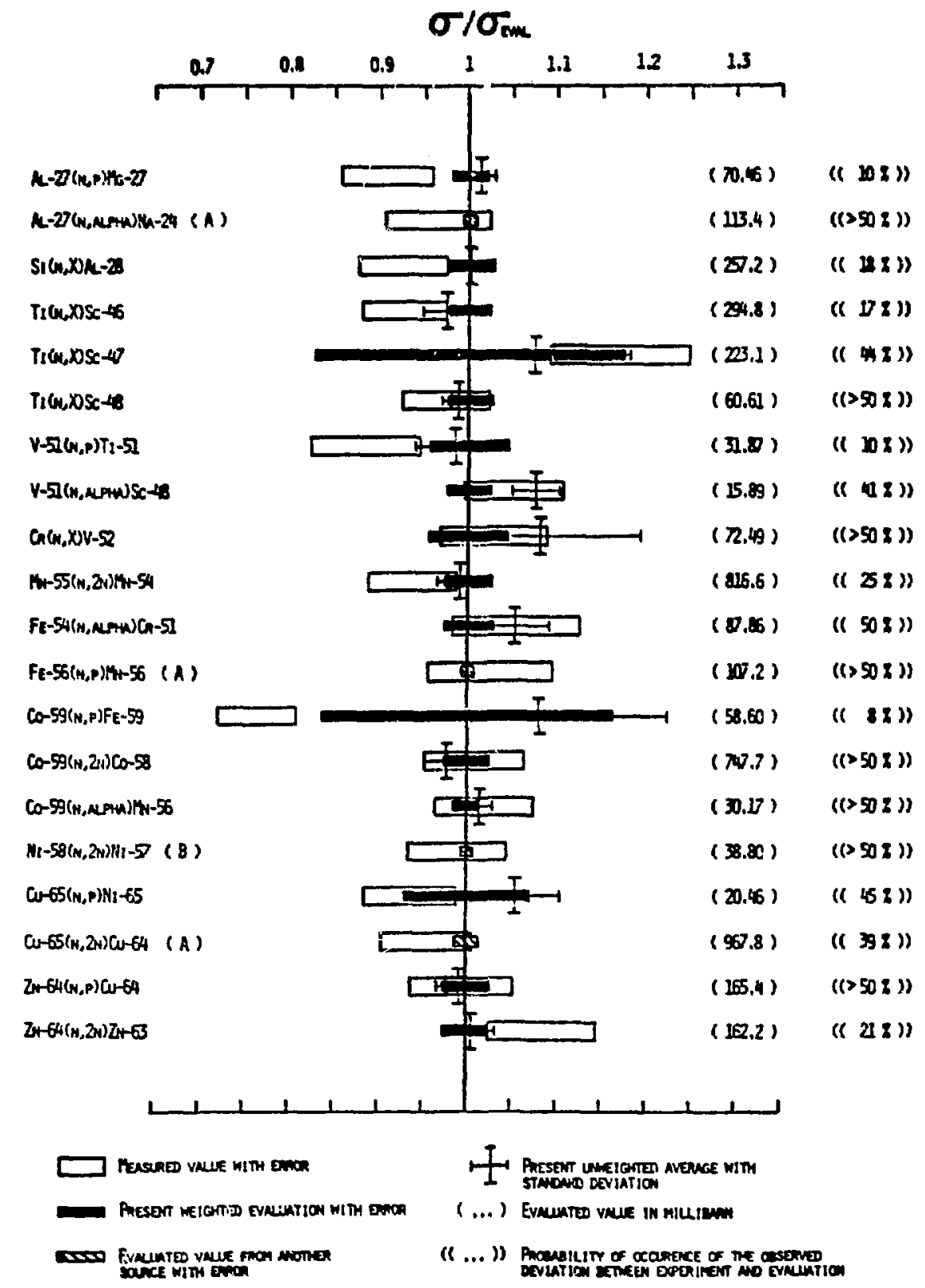

FICURE I Comparison of measured and evaluated 14.7-MeV cross sections. Evaluated values other than those from the present work are: (A) Ref. 8, (B) Ref. 9. 
uncertainties in the evaluations (including those from Refs. 8 and 9) range from 0.6 to $17.2 \%$. In rur opinion, evaluation errors smaller than 1 to $2 \%$ are probably too optimistic in view of the high probability for systematic errors at this level. Clearly, new measurements intended to reduce uncertainty to this level wili have to be very accurate in order to have any substantive impact.

Fig. I shows that, with few exceptions, the results of all of the present measurements are reasonabiy consistent with the evaluated results. This has been quantifled by calculating probabilities for the observed ceviations, assuming the evaluated results to be correct. These probabilities are shown by $((\ldots))$ in Fig. 1. In all instances the deviations are smaller than two combined (measurement and evaluation) standard deviations. The consistency is even better for the four best-known reactions, thereby providing confidence in our measurement procedures.

This work was supported by the U.S. Department of Energy.

\section{REFERENCES}

1. O.N. Jarvis, European Applied Research Reports-Nuclear Science and Technology, Vol. 3, Nos. I and 2, 127-352 (1981).

2. E.T. Cheng, D.R. Mathews and K.R. Schultz, GA-17324, General Atomic Company (1983).

3. CINDA-A (1935-1976), Vols. I and II-June 1979, CINDA-83 (19771983)-May 1983, CINDA-83 Supplement-November 1983, and CINDA$84(1982-1984)$-May 1984, International Atomic Energy Agency, Vienna, Austria.

4. Experimental Data File, CSISRS, National Nuclear Data Center, Brookhaven National Laboratory, Upton, N.Y., U.S.A.

5. B.P. Evain, D.L. Smith and P. Lucchese, ANL/NDM-89, Argonne National Laboratory (1985).

6. Table of the Isotopes, 7th Edition, ed. C.M. Lederer and V.S. Shirley (John Wiley and Sons, Inc., New York, 1978).

7. Evaluated Neutron Data File, ENDF/B-V, Surmary Documentation, compiled by R. Kinsey, ENDF-201, 3rd Edition, Brookhaven National Laboratory (1979).

8. G. Winkler and T.B. Ryves, Annals of Nuclear Energy, 10, 601 (1983).

9. G. Winkler, A. Pavlik, H. Vonach, A. Paulsen and H. Liskien, Nuclear Science for Technology, ed. K. Boeckhoff (D. Reidel Publishing Company, Dordrecht, Holland, 1983) p. 400.

10. D.L. Smith, J.W. Meadows, M.M. Bretscher and S.A. Cox, ANL/ NDM-87, Argonne National Laboratory (1984).

11. J.W. Keadows and D.L. Smith, ANL/NDM-60, Argonne National Laboratory (1984).

12. Handbook of Physics and Chemistry, 41 st Edition, ed. C. H. Hodgman (Chemical Rubber Pub. Co., Cleveland, Ohio, 1959) p. 210 . 